\title{
Pengaruh Kadar Garam Dapur Terhadap Suhu Makanan yang Dimasak dengan Microwave
}

\author{
Wasir Nuri \\ Jurusan Teknik Kimia Fakultas teknologi Industri \\ UPN"Veteran" Yogyakarta \\ Jln.SWK 104 Lingkar utara Condongcatur, Yogyakarta 55283. \\ Telp//Fax (0274)486889 \\ Email: wasirnuri_fti@yahoo.co.id
}

\begin{abstract}
Abstrak
Sebagian masyarakat ada yang memasak menggunakan oven microwave. Alasanya bermacam-macam antara lain untuk kesehatan dan sebagian lainya agar praktis. Mereka umumnya tidak mengetahui bahwa temperature masakan tergantung jumlah senyawa polar yang terkandung di dalam masakan. Garam dapur merupakan senyawa polar sehingga kandungan daram dapur berpengaruh terhadap suhu masakan. Pada penelitian ini dicari pengaruh kandungan garam dapur terhadap suhu masakan yang dimasak menggunakan oven gelombang mikro. Pada penelitian ini dilakukan simulasi dengan 20 gram pati ditambah 20 gram air garam dengan kadar garam bervariasi mulai 0 sampai 3.2 presen. Campuran dimasukan ke dalam gelas Becker $100 \mathrm{ml}$ dan dipanasi di dalam oven gelombang mikro pada tingkat daya rendah sampai medium, setiap 2,5 menit diukur suhunya sampai 15 menit. Hasil percobaan menunjukkan semakin tinggi kadar garam dan daya listrik tempertur sampel akan naik. Sebagai contoh pada kadar garam $0 \%$, posisi daya rendah dalam waktu 15 menit suhu sampel 37 ${ }^{\circ} \mathrm{C}$, naik menjadi $73{ }^{\circ} \mathrm{C}$ pada kadar garam $3,2 \%$, sementara pada persentase garam 0 dan daya pada posisi medium suhu naik menjadi $90{ }^{\circ} \mathrm{C}$.
\end{abstract}

Kata kunci :Garam, microwave, suhu.

\begin{abstract}
Many people cook by using microwave oven. There are some reasons for health and the others for practice. Generally they do not know that food temperature is depends on amount of polar compound. Salt is polar compound hence salt content influenced temperature of food. The objective of research was to determine salt content to food temperature which is cooked by microwave. This research was simulated by mixing $20 \mathrm{~g}$ starch and $20 \mathrm{~g}$ salt water with salt variation from 0 to $3,2 \%$. The mixed was put into Becker glass $100 \mathrm{cc}$. and heated in microwave oven in low power level until medium. The temperature was measured every 2,5 minute until 15 minute. This research show that salt and electricity power influence the temperature. For examples electricity power level-low, in 15 minute the temperature increase from $37^{\circ} \mathrm{C}$ to $73{ }^{\circ} \mathrm{C}$ at $3,2 \%$ salt content, while at salt $0 \%$ and electricity power medium level the temperature increase up to $90^{\circ} \mathrm{C}$.
\end{abstract}

Keywords : salt, microwave, temperature.

\section{Pendahuluan.}

Semakin maju suatu Negara semakin tinggi tuntutan terhadap hidup sehat, sehingga untuk memasak dipergunakan pemasak / alat menggoreng tanpa minyak, hal itu dimaksudkan untuk menghindarkan pengaruh minyak pada makanan, untuk maksut tersebut beberapa ibu rumah tangga memilih menggunakan alat pemasak gelombang mikro.

Menurut survei, $61 \%$ masyarakat sadar akan pentingnya teknologi pada peralatan rumah tangga untuk mempermudah kegiatan mereka kesehariannya. Sementara $41 \%$ lainnya memilih microwave sebagai salah satu alat masak yang praktis dan dapat membantu meringankan beban pekerjaan. (Muntaha, 2008).

Kelebihan memasak menggunakan oven gelombang mikro adalah panasnya merata, tanpa minyak goreng, higienes dan cepat. Tetapi belum banyak yang tahu bahwa memasak menggunakan microwave suhu masakan belum tentu sama dengan suhu masakan lainya, walaupun pemanasanya menggunakan derajat (tingkat) daya pemanasan yang sama. Oleh karena itu perlu diteliti factor yang mempengaruhi suhu pemasakan pada pemakaian oven gelombang-mikro.

Salah satu faktor yang berpengaruh terhadap suhu masakan adalah kadungan senyawa polar. Untuk keperluan penghematan energi atau untuk menaikkan suhu masakan dapat dilakukan dengan jalan menambah kandungan senyawa polar. Garam dapur adalah senyawa polar sehingga dengan menambahkan garam kedalam masakan suhu masakan akan lebih tinggi tanpa merubah daya pada alat pemasak dengan demikan dapat menghemat 
energi. Penelitian ini bertujuan untuk mencari hubungan kadar garam dapur terhadap suhu asakan yang dimasak menggunakan oven gelombang-mikro.

\subsection{Gelombang mikro.}

Gelombang mikro atau microwave dapat dijelaskan menggunakan persamaan Maxwell, menurut Maxwell bahwa sebuah medan magnetik yang berubah terhadap waktu bertindak sebagai sumber medan listrik dan sebuah medan listrik yang berubah terhadap waktu dapat bertindak sebagai sumber medan magnet. Medan listrik dan medan magnit ini dapat saling menopang membentuk sebuah gelombang elektromagnetik yang merambat melalui ruang. Gelombang electromagnet mengangkut energi dan momentum, medan listrik dan medan magnet merupakan fungsi sinusoida dari waktu dan posisi dengan panjang gelombang dan frequensi tertentu. Berbagai jenis gelombang elektromagnetik seperti cahaya, radio, sinar $\mathrm{x}$ dan lain-lainya hanya berbeda dalam frequensi dan panjang gelombangnya, gelombang electromagnet tidak memerlukan medium untuk merambat, kecepatan perambatan sama dengan kecepatan cahaya. (Young, 2003).

Menurut Maxwell jika sebuah muatan listrik bergerak dengan kecepatan tetap maka di sekitar garis lintasan akan timbul medan magnit dan medan listrik, muatan dipercepat agar menghasilkan gelombang elektromagnetik, muatan tidak memancarkan gelombang electromagnet sama besar kesegala arah, gelombang paling kuat pada pada arah tegak lurus terhadap sumbu gerak muatan, sementara searah dengan sumbu tidak ada gelombang. Dalam gelombagng besarnya medan listrik tidak sama dengan medan magnet. Dengan diketahui frequensi osilasi muatan akan dapat diukur panjang gelombang, dengan menggunakan persamaan :

$$
\mathrm{v}=\lambda f
$$

Medan listrik dan medan magnet bergerak tegak lurus tehadap arah perambatan dan medan listrik dan medan magnet saling tegak lurus satu dengan lainya, (lihat gambar 1). Karena kedua medan saling tegak lurus dan bergerak ke satu arah gelombang tersebut merupakan gerak tranfersal.

Energi yang dihasilkan gelombang mikro dapat dirumuskan sebagai berikut :

$$
\mathrm{u}=\frac{1}{2} \varepsilon_{0} E^{2}+\frac{1}{2 \mu_{0}} B^{2}
$$

Hubungan medan magnet terhadap medan listrik dinyatakan dengan persamaan

$$
\mathrm{B}=\mathrm{E} / \mathrm{c}=\sqrt{\varepsilon_{0} \mu_{0} E}
$$

sehingga

$$
u=\varepsilon_{0} E^{2}
$$

Aliran energi per satuan waktu per satuan luas

$$
\begin{aligned}
& \mathrm{S}=\varepsilon_{0} c E^{2} \\
& \mathrm{~S}=\frac{E B}{\mu_{0}}
\end{aligned}
$$

Oleh karena gelombang merupakan gelombang sinusoida maka besarnya setiap waktu tidak sama,

$\mathrm{S}_{\text {rata-rata }}=\frac{E_{\max } B_{\max }}{2 \mu_{0}}$

$\mathrm{S}_{\text {rata-rata }}=\mathrm{I}$,

(Young, 2003)

\subsection{Gelombang berdiri.}

Gelombang elektromegnetik adalah gelombang sinusoidal, sedang gelombang berdiri yaitu antara gelombang medan magnet berberda fase $90^{\circ}$ terhadap gelombang medan listrik, jika pada saat gelombang medan listrik minimum maka gelombang medan magnet maksimum, sehingga keduanya akan terjadi osilasi. Vektor medan listrik, vector medan magnet dan arah perambatan merupakan bentuk koordinat Cartesian yang bergerak maju (pada sumbu $\mathrm{x}$ ) dan berotasi melingkar pada sumbu $\mathrm{x}$ ini seperti gerak sekru, lihat Gambar 2. Tenaga yang ditranformasikan oleh gelombang yang berpolarisasi melingkar ratarata setiap waktu dua kali lebih besar dari pada gelombang yang berpolarisasi linier (Hasnadar, 2000).

Analisis yang detail terhadap gelombang berdiri medan listrik dan magnet berayun-ayun sebagai electron laser bebas, goyanganya merupakan konduksi polarisasi secara sirkel (berputar) dan linier (Tran 1982).

Alat pemasak dengan gelombang mikro gelombang elektromegnetiknya adalah gelombang berdiri, dengan panjang gelombang $12,2 \mathrm{~cm}$ atau jarak antara bidang simpul sebesar $6,1 \mathrm{~cm}$ atau setengah panjang gelombang (Young, 2003).

\subsection{Oven gelombang mikro}

Oven microwave adalah sebuah peralatan dapur yang menggunakan radiasi gelombang mikro untuk memasak atau memanaskan makanan, jika ada molekul air ditempatkan di dalam oven microwave maka air akan berputar dari putaran akan terjadi friksi sehingga timbul panas.

Baigan utama oven microwave umumnya terdiri dari: sebuah magnetron, magnetron control circuit, waveguide, dan ruang pemasak.

Oven microwave bekerja dengan memancarkan $\underline{\text { radiasi gelombang mikro, biasanya pada frekuensi }}$ $2.450 \mathrm{MHz}$ (dengan panjang gelombang 12,24 cm), melalui makanan. Molekul air, lemak, dan gula dalam makanan akan menyerap energi dari gelombang mikro tersebut dalam sebuah proses yang disebut pemanasan dielektrik. Kebanyakan molekul adalah 
dipol listrik, yang berarti mereka memiliki sebuah muatan positif pada satu sisi dan sebuah muatan negatif di sisi lainnya, dan oleh karena itu mereka akan berputar pada saat mereka mensejajarkan diri mereka dengan medan listrik yang berubah-ubah yang diinduksi oleh pancaran gelombang mikro. Gerakan molekuler inilah yang menciptakan panas (Lee, 2005).

Molekul air merupakan molekul dipool, artinya ada sisi atau kutub yang bermuatan negative dan sisi lainya bermuatan positive, menjadi seperti jarum kompas, jika salah satu kutub atau kedua kutub berada pada medan listrik yang sejenis berasal dari gelombang mikro maka akan terjadi gaya totak menolak menyebabkan molekul air akan berputar, dari rotasi tersebut akan timbul gesekan dan akan timbul panas (Lee, 2005).

Pemanasan oleh oven ini sangat efektif terhadap air, namun tidak begitu dengan lemak, gula, dan es. Pemanasan microwave kadang dijelaskan salah sebagai resonansi dari molekul air, hal ini terjadi hanya pada frekuensi yang jauh lebih tinggi, di sekitar 10 Gigahertz. U.S. Patent 2495429.

\subsection{Garam dapur.}

Garam dapur dengan rumus molekul $\mathrm{NaCl}$ merupakan senyawa polar dengan $\mathrm{Na}$ menjadi kutup positif dan $\mathrm{Cl}$ bermuatan dan merupajan kutup negative.

\subsection{Hipotesis.}

Semakin banyak kandungan senyawa polar dalam hal ini garam dapur di dalam bahan masakan, diperkirakan temperatur masakan akan semakin tinggi.

\section{Metodologi.}

Bahan yang digunakan pada penelitian ini adalah kanji, air dan garam dapur. Alat yang digunakan pada penelitian ini adalah Oven Microwave merk SHARP model R-108 SE, no seri 020819703, frequensi 2450 $\mathrm{MHz}$, daya input $960 \mathrm{Watt}$, daya output $600 \mathrm{Watt}$, power suply AC 220 Volt, dilengkapi dengan vasilitas tombol pengatur daya dari tingkat rendah, menengah rendah, menengah, menengah tinggi dan tingkat tinggi serta tombol pengatur waktu (timer).

Sampel dibuat dari campuran kanji dan air garam. Perbandingam kanji terhadap air garam sebesar $50 \%$ : $50 \%$ dan persentase garam di dalam air divariasi dari nol sampai 3,2 persen. Campuran dimasukkan ke dalam gelas Becker ukuran $100 \mathrm{ml}$ kemudian diaduk sampai homogeny, selanjutnya 10 gram sampel dimasukan ke dalam tabung reaksi ukuran $20 \mathrm{ml}$. Sampel dipanasi menggunakan oven gelombang mikro dan distel pada tingkat daya rendah 168 Watt (level low) dan tegangan 220 Volt. Setiap 5 menit suhu sampel dicatat. Percobaan diulang dengan daya oven gelombang mikro bervariasi mulai daya 330 Watt sampai 432 Watt. Diagram alir penelitian dapat dilihat pada gambar 1 .

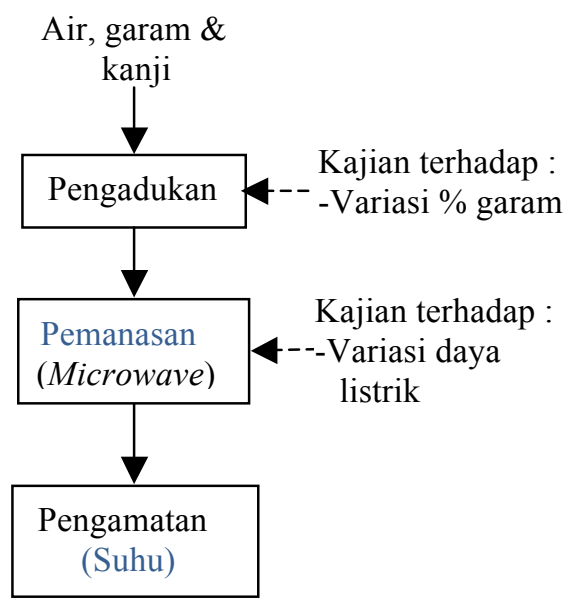

Gambar 1. Diagram alir penelitian

\section{Hasil dan Pembahasan}

Hasil percobaan pemanasan campuran kanji dan air garam menggunakan oven gelombang mikro dengan tegangan listrik 220 Volt, daya 168 Watt (low level) serta berat sampel 10 gram disajikan pada pada Gambar 2 .

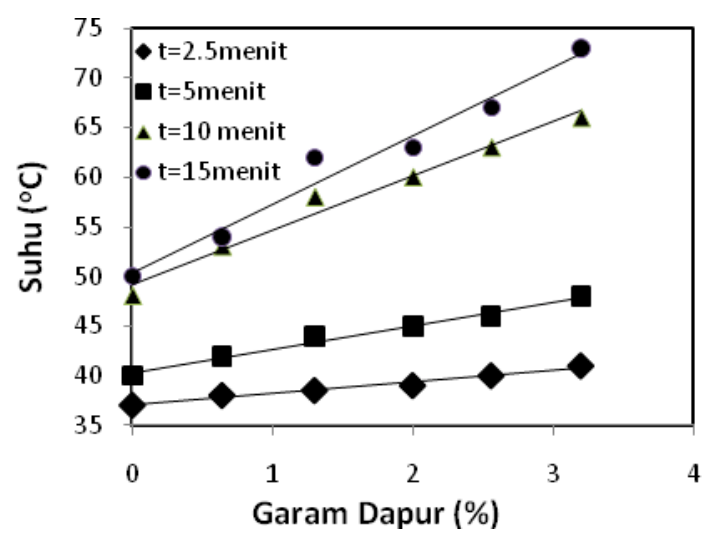

Gambar 2. Pengaruh kadar garam dapur terhadap suhu

Gambar 2 menunjukkan semakin besar persentase garam dapur menyebabkan suhu semakin tinggi. Sebagai contoh untuk waktu 15 menit suhu mulamula $50^{\circ} \mathrm{C}$ pada kadar garam nol persen naik menjadi $73^{\circ} \mathrm{C}$ pada kadar garam 3,2 persen. Hal ini karena jika persentase garam semakin besar maka senyawa yang berputar bertambah banyak. Garam merupakan senyawa polar yang akan berputar jika dikenakan radiasi gelombang elektromagnetik berdiri. Putaran molekul polar menimbulkan panas karena gesekan dengan molekul non polar (Lee, 2005), yaitu pati.

Hasil percobaan pengaruh persentase garam terhadap suhu sampel yang dipanasi enggunakan oven gelombangmikro dengan daya listrik divariasi 
dari 168 Watt (lowlevel), 330 Watt (médium low) dan 432 Watt (médium level) disajikan pada gamabr 3.

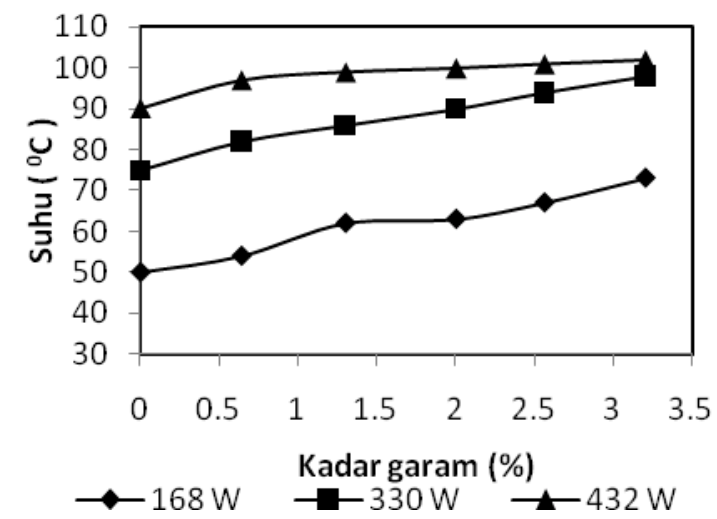

Gambar 3. Pengaruh daya listrik terhadap suhu

Gambar 3, menunjukkan bahwa semakin besar daya listrik suhu sampel semakin tinggi. Sebagai contoh percobaan pada waktu 15 menit persentase garam 3,2 dan dengan daya $168 \mathrm{Watt}$ (low level) suhu sampel $73^{\circ} \mathrm{C}$, suhu naik menjadi $98^{\circ} \mathrm{C}$ pada daya 330 Watt (medium low), dan naik lagi menjadi $102{ }^{\circ} \mathrm{C}$ pada daya 432 Watt (medium level).Hal ini disebabkan jika daya listrik naik maka putaran senyawa polar semakin kuat, garam merupakan senyawa polar, dengan putaran semakin kuat mengakibatkan friksi yang ditimbulkan oleh gesekan antara molekul polar terhadap molekul non polar semakin besar, dengan freksi yang semakin besar menyebabkan temperatur semakin tinggi.

\section{Kesimpulan.}

1. Kandungan garam dapur berpengaruh terhadap suhu masakan yang dimasak menggunakan oven gelombang mikro.

2. Semakin besar kandungan garam dapur di dalam masakan suhu akan semakin tinggi.
3. Pada persentase garam nol dan daya 168 Watt suhu sampel menunjukkan $50^{\circ} \mathrm{C}$ sedangkan pada persentase garam 3,2 suhu naik menjadi $73^{\circ} \mathrm{C}$ dalam waktu 15 menit.

4. Semakin besar daya listrik suhu masakan semakin tinggi.

5. Pada daya 168 Watt dan persentase garam 3,2 suhu sampel $50^{\circ} \mathrm{C}$ sedangkan pada daya 432 Watt suhu naik menjadi $102^{\circ} \mathrm{C}$ dalam waktu 15 menit.

\section{Daftar Arti Lambang}

B medan magnet, (Tisla)

E medan listrik, (Volt $/ \mathrm{m})$.

$f$ frequensi, (Hert)

I arus listrik, (Ampere)

$\mathrm{S}$ energi per satuan luas per waktu, (Joule $/ \mathrm{m}^{2} \mathrm{~s}$ )

$\mathrm{u}$ energi, (Joule)

$\mathrm{V}$ kecepatan cahaya, $3 \times 10^{8} \mathrm{~m} / \mathrm{s}$

$\lambda$ panjang gelombang, $(\mathrm{m})$.

$\varepsilon_{\mathrm{o}}$ permeabilitas medan listrik.

$\mu_{\mathrm{o}}$ permeabilitas medan magnet.

\section{Daftar Pustaka}

Haznadar, Z. and Stih, Z. 2000, Electromagnetic field, wave and numerical methods, IOS Press, p. 24, Islamabad.

Lee, 2000, How Microwaves Work, p.1-3, Colorado University, Colorado.

Lee, 2000, Method of treating foodstuff, U.S., Patent 2495429.

Muntaha, D, 2008, Kreatif Dengan Convection Microwave Oven, P.T. Electrolux Indonesia.

Tran, T., Danly, B., dan Wurtele, J., 1982, Free Electron Lasesr with Electromagnetic Standing Wave Wiggler, Issue 9, Vol 23, Quantum, Electronic, IEEE Journal, p. 1578, Lousanne.

Young, H.D. and Freedman, R.A., 2002, University Physics, $10^{\text {th. }}$ edition, Wesley Longman, Inc., California. 